\title{
Self-care/self-help strategies for persons with Ménière's disease: a systematic review
}

This article was published in the following Dove Press journal:

Patient Intelligence

19 November 2015

Number of times this article has been viewed

\author{
Andrew F Long' \\ Alison Brettle ${ }^{2}$ \\ 'Health Systems Research, School \\ of Healthcare, University of Leeds, \\ Leeds, UK; ${ }^{2}$ School of Nursing, \\ Midwifery and Social Work, University \\ of Salford, Salford, UK
}

\begin{abstract}
In recent years, health care practitioners and researchers have become increasingly interested in finding ways to help persons with long-standing health problems cope and live their everyday lives. This article presents the findings of the first systematic review of empirical research on the self-care strategies that persons with one such condition, Ménière's disease (MD), find helpful. It aims to provide evidence-informed guidance to persons with MD on self-help/self-care approaches they might pursue. Searches were undertaken on three databases (MEDLINE, CINAHL, and PsycINFO), locating 239 potentially relevant references relating to MD or symptoms associated with the condition. Following a screening and critical appraisal process undertaken by the authors, eight papers were included in the review and were judged to be of high or good quality. The papers were synthesized in a narrative form, with individual papers summarized in evidence tables. No single self-help/self-care strategy or coping mechanism was evident. The review found evidence of the potential of a diverse range of helpful self-care approaches, including a cognitive behavioral therapy-self-help intervention, changes in lifestyle, developing and adopting positive approaches and/or avoidance of precipitating factors, and complementary and alternative medicine. The key message, for persons with MD and their caring health practitioners, is to become aware of the multiplicity of potential strategies and to try with support from others to "find what works, why and how" for themselves in their own psycho-socio-cultural lifeworld. More research is needed to examine people's search for self-care strategies and obtain insight into how and why these work for them, drawing on notions of pragmatic acculturation, health literacy, and human/health agency, in addition to further research on the potential of, and who might benefit most from, cognitive behavioral therapy-self-help interventions.
\end{abstract}

Keywords: self-care, coping strategies, Ménière's disease, systematic review

\section{Background and introduction}

In recent years, an increasing focus has centered on uncovering and identifying ways that persons with a chronic illness or long-standing condition employ and find helpful in enabling them to cope and live their everyday lives. This is particularly the case when bio-medical treatments have substantial side effects (eg, chemotherapy for cancer), are unacceptable to the patients, or their treatment has run its course with little or no amelioration of the symptoms, but still significantly impact their quality of life (QoL). Alongside, health care practitioners and researchers have tried to identify and develop supportive self-help strategies for patients to enable them to help themselves, and as a way of delivering both more efficient and potentially more effective and cost-effective resource use in view of the exploding costs of health care services.
Correspondence: Andrew F Long Health Systems Research, School of Healthcare, University of Leeds, Rm I.I I Baines Wing, Leeds, LS2 9UT, UK Tel +44 I I3 3436250

Email a.f.long@leeds.ac.uk 
Within both the medical sociology and health psychology literature, much theoretical and research work has centered on coping and coping strategies for those with chronic illness. Bury's influential writings ${ }^{1,2}$ talk about chronic illness as "a disruptive event" ("biographical disruption" of their takenfor-granted health and role in society, their life and socioeconomic life-world) and development of ways to respond to these disruptions. Bury ${ }^{2}$ distinguishes two sorts of meaning associated with having a chronic illness: "meaning as consequence" (the problems created for the individual and their everyday activities, QoL, and social role) and "meaning as significance" (the significance of the illness and its presentation to others). ${ }^{3,4}$ Another stream is evident in Antonovsky's ${ }^{5}$ concept of the sense of coherence (SOC) and self-resiliency and how and why some people remain healthy and others not (a focus on salutogenesis). ${ }^{6}$

Yet other concepts are addressed within health psychology, building on influential work from, for example, Folkman and Lazarus, ${ }^{7}$ exploring stress and coping mechanisms and individuals thinking about how to respond. Within health psychology, coping is perceived as a combination of cognitive and behavioral efforts and coping mechanisms are developed through individuals' thought processes. These works and subsequent work by others ${ }^{8}$ have identified many hundreds of coping strategies. These have been helpfully classified into three broad types: appraisal-focused (directed to challenging one's assumptions); problem-focused (directed at reducing or eliminating the stressor); and emotion-focused (directed toward modifying one's emotional reactions). ${ }^{8}$ Yet others draw on both theoretical perspectives. ${ }^{9}$ In addition, there is the notion of self-efficacy ${ }^{10}$ or, within sociology, self/humanagency ${ }^{11}$ and empowerment, ${ }^{12}$ each with different but related emphases. Self-efficacy centers on a person's self-perceived ability to have control, self-agency to "act to further their (own) interests", ${ }^{12}$ and empowerment on issues of control, ways to promote empowerment, and regaining personal control.

Another set of theoretical literature explores the meaning of, and differentiation between, self-care and selfmanagement. ${ }^{13}$ This is important as the terms are often used as if they were interchangeable and/or without providing a clear definition of what is meant. However, there are key areas of difference. Self-management concerns the active engagement of patients in their treatment and their collaboration with health care practitioners in the management of their condition. Patients are to work with the health care professionals and follow through their recommendations, for example, dietary changes or broader behavioral modifications (reducing smoking, focusing thinking onto the present). ${ }^{14}$
Self-care on the other hand concerns choices and modifications made by individual patients by and for themselves in order to enhance their health or prevent ill-health. These may come about from reflection on advice from others (for example, family, friends, and also health care professionals) and their own, personal experiential knowledge. Examples include decisions to take up more exercise, make dietary changes, and/or avoid certain situations or circumstances to minimize a possible negative ill-health experience or social embarrassment, as well as consulting with complementary and alternative medicine (CAM) practitioners for their help. Foremost are issues centered on the personal experience of the patients, their choice and decision, with all potentially highlighting gaining or regaining control over their life within their own lifeworld. Emphasis lies on the individual's selfagency and search for self-empowerment.

The focus in this paper is on self-care. Drawing on this terminological differentiation and a recent, high quality systematic review of definitions of self-care within published policy and practice research, ${ }^{15}$ it is evident that the concept of self-care is multi-layered, centered on things the persons do for themselves to enable coping in their lifeworld, drawing on their own and/or others' experience or advice and support from significant others (for example, partner, sibling, and close friends). More formally, self-care can be defined as:

Involv(ing) a range of care activities deliberately engaged through life to promote physical, mental and emotional health, maintain life and prevent disease [....] performed by the individual [....]. Self-care activities include social support and the meeting of social and psychological needs. ${ }^{15}$

One significant chronic or long-standing condition is Ménière's disease (MD). MD is a long term, progressive disease which damages the balance and hearing parts of the inner ear. Onset of MD may be mono-symptomatic, commonly with one ear being affected. As a consequence, diagnosis may be difficult and delayed. There is substantial disagreement in the literature about incidence and prevalence rates of MD. Estimates for incidence range from 8/100,000 (Italy) to $45 / 100,000$ (England) and prevalence from $0.4 \%$ to $1.0 \%$. Substantial within-country variation is also evident. ${ }^{16}$ The disease may become bilateral, commonly within 5 years. Attacks of vertigo reach maximum severity as the disease develops and subsequently the attacks become less severe, not so frequent, and eventually disappear. ${ }^{17}$ In approximately $50 \%$ of cases, attacks cease after 2 years and in $75 \%$, attacks have ceased after 8 years. ${ }^{18}$ Its etiology is not fully understood. In a literature-based clinical review of the diagnosis and treatment 
of MD, possible risk factors identified included: viruses; vascular involvement, and an association with migraine; genetic predisposition in a small percentage of cases; immune system involvement; and psychological factors. ${ }^{17}$

Moreover, there are no necessarily effective ways to medically treat or manage the condition. Saeed observed that "currently, the treatment of MD is empirical. As yet, no treatment has prospectively modified the clinical course of the condition and thereby prevented the progressive hearing loss". ${ }^{17: 369-370}$ Conventional biomedical treatments are drugs (recent evidence suggests the particular value of low dose gentamicin), ${ }^{19}$ diet, and surgery. In addition, some patients explore CAM therapies to help alleviate symptoms and promote their health and healing. The lack of effective biomedical treatments reinforces the significance and importance of self-care in identifying ways that persons with the condition self-use and find helpful. This lack has also encouraged health care practitioners to develop and design supportive interventions (such as leaflets, credible web-based information, and/ or self-help care packages, including cognitive behavioral therapy [CBT] oriented approaches) for helping the persons manage and cope with their MD.

This article presents the findings of the first systematic review of empirical research on self-help/self-care strategies that are used by persons with MD to assist in their living with this condition. The review question is: Identify and document self-care/self-help strategies for persons with MD.

The overall aim is to provide evidence-informed guidance to persons with MD on the self-help approaches they might consider trying and incorporating into their own lives in order to assist their coping with their illness.

\section{Methods}

\section{Search strategies}

Searches were undertaken on three health care databases representing perspectives most relevant to the topic area: MEDLINE (Ovid) (biomedical), CINAHL (EBSCO) (nursing and allied health), and PsycINFO (Ovid) (psychological). In addition, a search was undertaken on Google Scholar and a snowballing approach taken to track citations from key articles and major authors in the field. No date restrictions were applied. Included papers had to report findings from an empirical study or a review of the literature and be written in the English language (as there were no resources for translation).

A range of keywords were employed. They covered theoretically-informed key terms of: self-care, selfmanagement, self-treatment, self-efficacy, self-agency, empowerment and control, and sense of coherence. These were allied with the key terms of coping and coping strategies. The terms were then combined with terms related to MD, including vertigo, tinnitus, dizziness, and endolymphatic hydrops to ensure that a wide range of relevant self-care/self-help related articles were located. Figure S1 is an illustrative search strategy for PsycINFO . Following citation tracking, an additional search using the term positive experiences, combined with MD, was undertaken to identify reports on experiences that might be either positive or, as is more common, reporting only on the negative experiences (impact) of the condition.

Initial searches before citation tracking located 239 potentially relevant references (Figure 1). These were first screened by $\mathrm{AB}$, drawing only on the information contained in the title and abstract, to identify papers of likely relevance to the topic area. This resulted in 89 potentially relevant articles. These were then rescreened by AFL to identify those relevant to the focus of the systematic review, resulting in 13 papers. Their full texts were obtained and read by AFL, with any not relevant excluded at this point. Interest centered on the self-care/self-help strategies employed and not on identifying which were most or least effective in a meta-analysis sense. Non-systematic or literature reviews of CAM or biomedical treatment reviews were excluded as well as studies, for example, exploring correlations of components of existing measures or those reporting impact on QoL without reporting on self-help strategies or coping mechanisms. Citation tracking was then undertaken, identifying an additional 25 papers. Four were identified as relevant to the self-help review, one of which was a systematic review which included eight studies all identified in the citation tracking.

Eight papers formed the set of literature for the systematic review, all focusing directly on MD. Two other studies, one exploring self-help strategies adopted by persons with vertigo $^{20}$ and a systematic review of CBT self-help approach for tinnitus, ${ }^{21}$ were critically appraised and used only to reinforce the findings of papers included in the systematic review, as both vertigo and tinnitus are common, major features of MD with which persons suffering from this condition have to cope. In keeping with the review question, heterogeneity of research styles, underlying theoretical perspective and research aims (ranging from stress-related coping, CBThealth practitioner-designed self-help packages, self-help strategies developed by the person with MD to positive experiences), a narrative review of the evidence is provided. ${ }^{22}$

\section{Critical appraisal}

Each included study was appraised by AFL, with an independent review conducted by $\mathrm{AB}$. Three approaches were taken. 


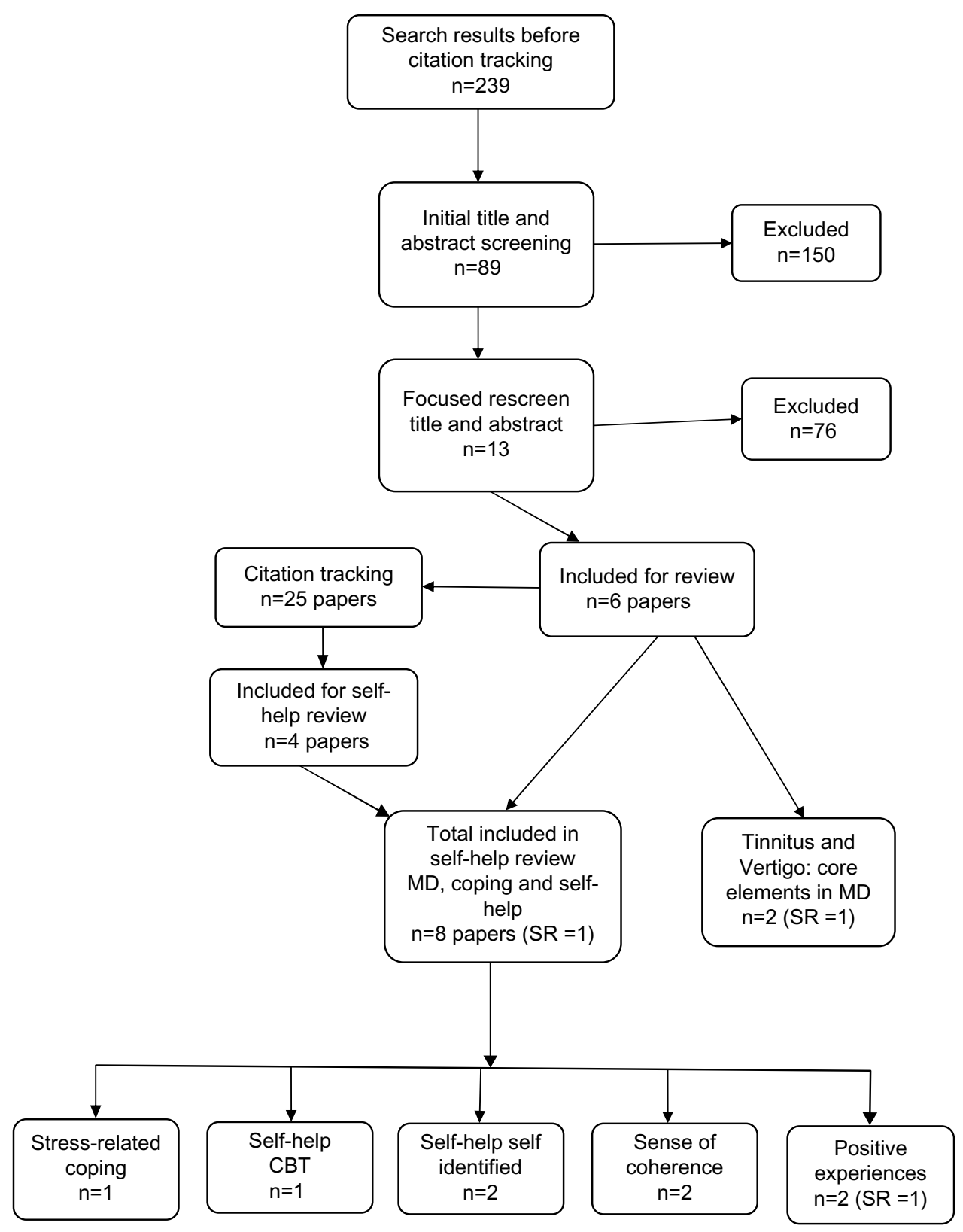

Figure I Flow chart of review process.

Abbreviations: CBT, cognitive behavioral therapy; SR, systematic review; MD, Ménière's disease.

Firstly, drawing on Boonstra et al, ${ }^{23}$ the study's underlying theoretical perspective was identified. This information is important to collect in order to uncover the theoretical standpoint/lens which informs both the study design and the authors' interpretation of the findings. Secondly, an established comprehensive evaluation tool ${ }^{24,25}$ was used to draw out key features of the study and identify its strengths and weaknesses. Thirdly, use was made of a quality of study rating form ${ }^{26,27}$ to draw out a quantitative summary of study quality as a percentage (the higher the percentage, the greater its perceived quality) and NICE quality appraisal checklist tools ${ }^{28}$ categorizing the overall strength of evidence according to the following criteria: ++, high quality; +, good quality; and -, low quality. Following the recommendation of the designers of the quantitative summary of quality, a score at either end ( 0 or 4$)$ of the rating for the relevant item was given for maximum reliability. In addition, only relevant items were scored, with the maximum score (before conversion to a percentage) being the total number of relevant questions, given the study type, times the maximum score (4) per item. Applying the quantitative summary of quality in this way may thus over-state its quality. 


\section{Results}

\section{Nature and quality of the evidence}

An overview of each study included in the systematic review, summary evaluative comments, and overall evidence quality judgments are presented in Table 1. Six studies ${ }^{31-35,38}$ drew on European participants, with one ${ }^{29}$ also including participants from Australia; while the systematic review ${ }^{30}$ had no country limitation, studies meeting the inclusion criteria were conducted in Europe. A range of study types was used: four cross-sectional studies; $;{ }^{31-34}$ two qualitative studies, ${ }^{29,35}$ with one using a narrative design ${ }^{29}$ a systematic review; ${ }^{30}$ and one randomized controlled design..$^{38}$

The papers were generally of good quality. The quantitative summary of quality scores ranged from $75 \%$ to $96 \%$. Five of the papers were judged as of "high quality" and the remaining three of "good quality" on the NICE quality appraisal criteria. ${ }^{28}$ Application of the evaluation tool identified a number of strengths and weaknesses for the studies. The strengths included: sound study design and execution; clarity and good detail on the intervention used; use of validated questionnaires, accompanied sometimes by appropriate open-ended questions; the authors' conclusions judged to fit the presented findings; and, in one instance, ${ }^{29}$ presentation of an empirically-informed model of the search for coping strategies to guide future research. In addition, it is notable that the studies included in the systematic review of positive experiences, either by the person with MD or their significant others, were generally of high quality. Potential weaknesses included: sample selection (dependence on volunteers, though recruited in sound ways; samples predominantly drawing on those who chose to be members of the national or regional Ménière's Association/Federation - members might be expected to have experienced a more severe impact of the condition and/or be keen to find out how they compare with others) $;{ }^{39}$ small sample sizes; and queries over whether or not there was "definitive" diagnosis of the particular condition. Approaching members of Ménière's Association/Federation is difficult to avoid as there is no other list or register of persons having MD. In addition, the authors commonly pointed to key study limitations, including, for some, restricted generalizability.

\section{Theoretical perspectives}

Table 2 provides insight into the underlying theoretical perspectives that informed each study design and interpretation of the findings, grouped by the type of self-help approach. Underlying theories ranged from psychology (CBT-based), socio-psychology, ${ }^{7,40}$ positive psychology, ${ }^{41}$ to an illness disruption perspective, a whole-system, and whole-person mind-body perspective ${ }^{42,43}$ and the sociological perspective of salutogenesis. ${ }^{5}$ Only one study ${ }^{34}$ did not explicitly refer to any specific theoretical orientation; however, its focus on uncovering individuals' self-help techniques suggests a self/ health agency perspective.

\section{Supportive strategies}

Five sets of supportive strategies/self-help approaches were identified: stress-related coping strategies; CBT approaches, drawing on health care practitioner-designed booklet and web-based information resource; self-identification of selfhelp strategy; SOC; and reflecting and building on positive experiences. The studies presented evidence in one form or other (self-perceived/stated or validated questionnaire responses), at a minimum implying features supporting a self-help strategy. For example, a cross-sectional study, ${ }^{32}$ which included two reference groups, enhancing confidence in the findings, found that a firmer SOC correlated strongly with better QoL and that the SOC was also the best predictor of self-rated symptom-specific QoL.

\section{Stress-related coping strategies}

One study on persons with $\mathrm{MD}^{31}$ identified four main coping strategies aimed at reducing the impact of dizziness experienced: escape from or avoidance of being in the seeming trigger situation(s); "self-controlling", by trying to control/ regulate one's feelings and actions, thus attempting to make things better in the situation; "distancing oneself" in a potentially negative way, through modifying their attitude to or reducing the perceived importance of the situation or event; and "accepting responsibility", trying to address the situation directly. They also observed that anxiety sensitivity in relation to dizziness was strongly correlated with perceived emotional handicap from dizziness and, less strongly, to reported overall discomfort with MD. It is interesting to note here that a qualitative study that focused only on self-help strategies identified by persons with dizziness (and not MD) ${ }^{22}$ (Table S1) identified two of these strategies: developing and adopting a positive approach, for example, "carrying on as usual" (characterized as "courageous coping") and avoidance of precipitating factors (for example, restricting their work or social activities, sitting/lying down, or holding on to a support), This study also drew attention, as with many others, to the importance of supportive significant others, ranging from family members and friends to work colleagues (an ability to draw on them for support and advice), approaches aimed at improving their lifestyle (including dietary changes, smoking, and exercise) and involvement of medical or other 
Table I Evidence table of included studies

\begin{tabular}{|c|c|c|c|c|}
\hline Study & Main study objective & $\begin{array}{l}\text { Study type, country and } \\
\text { recruitment source }\end{array}$ & $\begin{array}{l}\text { Treatment and } \\
\text { participants }\end{array}$ & $\begin{array}{l}\text { Confirmed diagnosis } \\
\text { and length of time with } \\
\text { condition }\end{array}$ \\
\hline \multicolumn{5}{|c|}{ Stress-related coping strategies } \\
\hline $\begin{array}{l}\text { Hägnebo et } \mathrm{al}^{31} \\
\text { (1999) }\end{array}$ & $\begin{array}{l}\text { To investigate if stress-related } \\
\text { coping strategies predicted } \\
\text { perceived handicap for } \\
\text { dizziness, reported discomfort } \\
\text { from illness, and anxiety } \\
\text { sensitivity in persons with MD }\end{array}$ & $\begin{array}{l}\text { Swedish cross-sectional } \\
\text { survey, using postal } \\
\text { questionnaires and } \\
\text { correlational analysis } \\
\text { Recruitment from a MD } \\
\text { patient association (II7 } \\
\text { members) in one city }\end{array}$ & $\begin{array}{l}\mathrm{N}=50 ; 65 \text { completed } \\
\text { questionnaires (response } \\
\text { rate, } 56 \% \text { ); I } 5 \text { not meeting } \\
\text { eligibility criteria (I " "no } \\
\text { exposure" to stress; four } \\
\text { due to unconfirmed MD) } \\
\text { Respondents: } 32 \text { ( } 64 \% \text { ) } \\
\text { female; mean age of } 56 \text { years }\end{array}$ & $\begin{array}{l}\text { Medical diagnosis reported } \\
\text { by participants } \\
\text { Mean MD duration of } 12 \text { years }\end{array}$ \\
\hline
\end{tabular}

\section{Self-help - cognitive behavioral therapy (CBT) approach}

Yardley and Evaluate if booklet-based $\mathrm{Kirby}^{38}$ (2006) education in symptom management and CBT techniques could help in management of vertigo and dizziness

\section{Self-help - "finding your own way"}

\section{Long and Identify significant events}

Bennett $^{29}$ (2009) for persons searching for complementary and alternative medicine (CAM). The ways they coped with the impact of MD and their use of CAM and perceived benefits.
UK randomized controlled trials, (2 intervention, I WLC)

Recruitment in 2003: all, members of the UK Ménière's Society $(n=4,800$;

381 expressed interest; 360 met eligibility criteria) Ethically approved study

Narrative design and documentary analysis; qualitative research UK and Australia (Victoria) Recruitment, 2004-2005 via web sites of UK and Australia Ménière's Societies Ethically approved study
WLC; $N=360 ; 120$ participants Confirmed diagnosis unclear in each of the three groups 6 months, $5 \%$ drop-out overall Treatment: VR, to promote adaptation within the balance system, designed by health care practitioner SC using applied relaxation, controlled breathing, and cognitive behavioral strategies WLC

$\mathrm{N}=20$ participants' stories of experience with MD and use of CAM (UK, I5; Australia 5), 23 letters in UK newsletter, Spine

UK: Two-thirds female; median age, 58

Australian: all female; median age, 59 (although highly likely)

Time with MD not stated
Confirmed

Median time with MD:

I I years (UK) and 2 I years

(Australia) 
Key findings
Summary evaluation comments
Overall

evidence

quality*
Three coping strategies correlated with dizziness: escape/avoidance and distancing positively and self-controlling negatively. Accepting responsibility and escape/avoidance correlated with anxiety sensitivity.
At 3 and 6 months: both VR and SC groups reported improvement vs WLC (6 months: $38 \%$ VR, $39 \%$ SC vs $16 \%$ WLC); both VR and SC significantly different from WLC but not from one another. Patient enablement scores significantly higher.

Significant difference in adherence between VR and SC (50\% SC vs $38 \%$ VR), and greater improvement for those reporting adherence.
Findings demonstrate personal nature and diversity of participants' journeys in their search for better, and nonbiomedical, ways to cope with their $M D$, and role of significant events (eg, increased attack frequency or severity of the condition) and others (eg, family member, friend, GP) in influencing or helping them in their search. No single CAM approach or pathway was evident. The most common CAMs used were energy-related (eg, acupuncture, reflexology), herbal and vitamin supplements, and dietary changes.

"Finding your own way" depicted the diversity in journeys in finding ways to cope with MD.
The study is well designed and uses used a set of validated postal questionnaires to explore the study objective. The sample size is on the small side for substantial confidence, and thus wider generalization, to be placed in the resultant correlation sizes. The findings are well discussed in relation to general coping strategies and associated literature, adding to the strength of the study. The authors pointed to some study including: reliance on self-reported medical diagnosis of MD, use of a volunteer non-random sample and a problematic, low response rate. In general, it is likely that those most bothered by MD would take part in the study.

The authors' conclusion that cognitive and behavioral factors should be taken into account in medical management and counseling is supported by the correlational evidence.

Novel and useful first study of VR in MD and comparison of VR and SC and selfhelp booklets, designed by health care practitioners. RCT soundly conducted, appropriate participant recruitment source, good detail on intervention, sample size based on previous study with $90 \%$ power and $5 \%$ significance level to detect effect size of $d=0.5$, appropriate outcome measures (self-perceived health-related) and adequate follow-up time and low loss to follow-up.

Authors pointed to some study limitations (volunteer sample; possible that those perceiving they were most in need of the offered interventions more likely to agree to participate). Sustainability of use of VR and SC remains for future study. Authors' conclusion (self-help management booklets may result in greater subjective improvement in health and confidence in understanding and coping) fits the evidence.

Implications: Potential of self-help booklet, based on VR and SC, to offer an inexpensive, non-harmful, and effective means of addressing unmet information needs and increasing sense of well-being and control over the illness.

Appropriately conducted narrative study soundly conducted. Guidance provided to participants on material sought; strong theme-based qualitative data analysis approach (multiple readings; identifying effects, approaches and experiences with CAM use in multiple phases of their illness trajectory; identification of themes) and conducted by the two authors independently; interpretation of patient account plausible and research-based ("their interpretations of situation" at time of writing) ${ }^{36,37}$ Study presents a model (appropriately depicted as tentative and requiring further research with other participants) of coping strategies (including CAM) for MD.

Authors draw attention to study limitations (small-scale; participants volunteers who responded to the advertisement about the project; participants more likely those who had tried CAM with some success) and strengths (personal stories, conduct of study; presentation of theoretical model of search and coping strategies).

Authors' conclusion (potential role of CAM therapies in helping people with MD find better ways to self-manage their symptoms and limit MD's impact on their lives) fits the data.

Implications: potential role of CAM as a complementary/additional way to assist in managing MD; potential for bio-medical practitioners to mention it to their patients to aid earlier location of effective ways to cope with MD. 
Table I (Continued)

\begin{tabular}{|c|c|c|c|c|}
\hline Study & Main study objective & $\begin{array}{l}\text { Study type, country and } \\
\text { recruitment source }\end{array}$ & $\begin{array}{l}\text { Treatment and } \\
\text { participants }\end{array}$ & $\begin{array}{l}\text { Confirmed diagnosis } \\
\text { and length of time with } \\
\text { condition }\end{array}$ \\
\hline $\begin{array}{l}\text { Kentala et } \mathrm{al}^{33} \\
(2013)\end{array}$ & $\begin{array}{l}\text { Explore self-reported } \\
\text { approaches to MD and } \\
\text { the ways in which these } \\
\text { could be used to help } \\
\text { other patients }\end{array}$ & $\begin{array}{l}\text { Postal questionnaire sample } \\
\text { survey } \\
\text { Finland } \\
\text { Recruitment date unspecified; } \\
\text { Every sixth patient on } \\
\text { FMF's membership list, } \\
228 \text { contacted, I } 83 \text { returned } \\
\text { questionnaire } \\
\text { (80\% response rate) } \\
\text { Ethically approved study }\end{array}$ & $\begin{array}{l}\text { Participant's self-use of } \\
\text { approaches to managing MD } \\
\text { at time of sample survey } \\
\text { Participants: } 80 \% \text { female, } \\
\text { mean age } 62 \text { (SD I0) }\end{array}$ & $\begin{array}{l}\text { Unclear if medically confirmed } \\
\text { diagnosis. } \\
\text { Mean age of onset of MD } \\
44 \text { years }(S D=13) \text {, All with } \\
\text { chronic MD and not at } \\
\text { acute stage }\end{array}$ \\
\hline
\end{tabular}

MD: sense of coherence (SOC)

Soderman et $\mathrm{al}^{32}$ Assess self-rated quality of life (200I)

Ketola et $\mathrm{al}^{34}$ (2014) associated with vertigo, loss of hearing, and tinnitus in patients with MD and identify SOC

Investigate the SOC in relation to specific symptoms, positive experiences, and participation restrictions in $M D$ and their effect on the impact of MD and QoL
Cross-sectional,

questionnaire-based study,

with two reference groups

Sweden

Tertiary treatment center,

Karolinska or Skövde; and

Stockholm County

MD patients, fulfilling

eligibility criteria

Reference group of random sample of population and patients with any peripheral vestibular disorder Ethically approved study

Cross-sectional study Questionnaire mailed to every sixth member of FMF; contacting 228 persons. Each sent a 26page questionnaire $->181$ respondents.

A second questionnaire sent out to remainder of FMF members $->366$ replied. Total sample size 547. Ethical approval not required under Finnish law for this sort of study.
124 who met eligibility criterion (definite MD invited); $\mathrm{N}=$ I I 2 (90\%) agreed to participate Reference group $\mathrm{n}=\mathbf{2 8 8}$ (268 general and 20 other) MD patients 53 , mean age and range of 28-75 (depending on previous or no medical treatment); approximately $50 \%$ were female

Questionnaire covering: vertigo $E Q-5 D$, tinnitus, hearing disability participation restriction and SOC (13-item SOC). Also open-ended questions asking "are there ways you can relieve or prevent your condition? If so, please list ..."; and list impacts of MD. Participants: $80 \%$ female; mean age $6 \mathrm{I}$ yrs. $(\mathrm{SD}=\mathrm{II})$
Confirmed

5 years for $60 \%-65 \%$
Confirmed. Mean age at MD onset 43 years $(S D=13)$ 


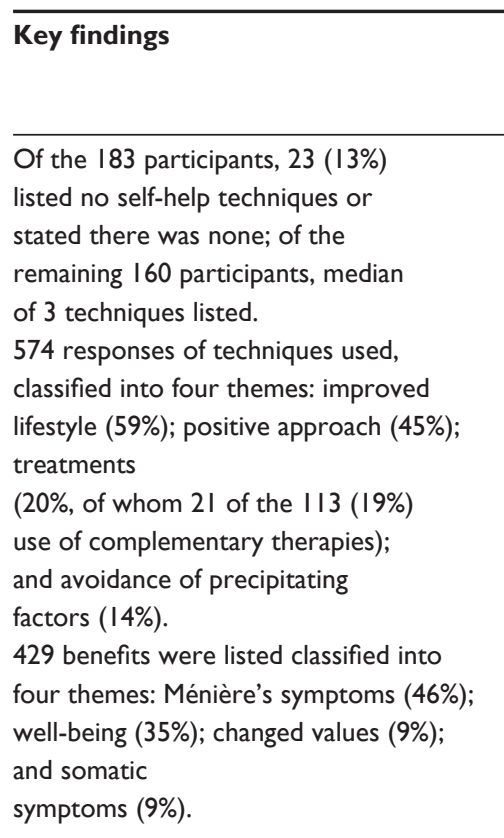

Most respondents indicated good or very good QoL, with no difference in the treatment and reference groups. The SOC scale (ability to cope in stressful situations) showed a strong correlation to reported QoL, and in the regression analysis was the strongest predictor of self-rated symptom-specific QoL (ie, vertigo symptoms, hearing disability handicap, and tinnitus severity).
Summary evaluation comments

Simple concurrent, cross-sectional sample, using list sampling (which could lead to bias if ordering in the list). As participants were representative of all members of FMF, confidence in generalizing results to that group. Sound study design for study aim and good coverage of questionnaire (copy not provided with article). Good response rate (80\%).

Authors do not discuss any strengths or weaknesses of the study. Authors' conclusion (self-help mainly was aimed at SC and improving well-being, with most focused on changing lifestyle) fits the reported findings. Authors suggest need for health care professionals to promote patients' positive thinking and attitude change, incorporating this into their treatment options. They also suggest the potential of designing a web-based tutor for MD patients, drawing on their findings. Authors caution and suggest, though not based on study evidence, that tailored self-help can be potentially better achieved via the internet than booklets, though it challenges reliability and accessibility of information thereon.

This is a well designed and conducted study. The sample is of good size and the study is strengthened by the inclusion of two reference group samples. Agreement of the findings to other studies in the area is pointed to and careful and appropriate conclusions are drawn from the study as well as the need to examine long-term positive effects.

The study has a two-part design for which the sample drawn for the second part is somewhat unclear. i) Greater insight is needed into the rationale for the two-part design. The first part of the design and numbers responding is identical to that reported in Stephens et al, ${ }^{56}$ raising a question whether in fact this is the same set of persons and data. This needs clarification. ii) The total response rate is unclear. iii) Greater clarity is needed over why the two sets of respondents from the two-part design are merged together for the data analysis reported in this paper. This is important to know as studying only the second set of participants $(n=366)$ would have resulted in an adequate, good sized sample.

One might query the scope of The authors' comment that individuals can be "deliberately trained, thus improving coping ability".

However, despite referencing an earlier study to support this (Soderman et $\mathrm{a}^{27}$ $200 \mathrm{I}$ ), whether this is the case would need to be demonstrated in other research.

The authors' conclusions relating to the SOC (those with higher scores more content with their QoL and value of positive attitudes) fit the findings presented in the study. 
Table I (Continued)

\begin{tabular}{|c|c|c|c|c|}
\hline Study & Main study objective & $\begin{array}{l}\text { Study type, country and } \\
\text { recruitment source }\end{array}$ & $\begin{array}{l}\text { Treatment and } \\
\text { participants }\end{array}$ & $\begin{array}{l}\text { Confirmed diagnosis } \\
\text { and length of time with } \\
\text { condition }\end{array}$ \\
\hline \multicolumn{5}{|c|}{ MD: (building on) positive experiences (of persons with MD and/or their significant other) } \\
\hline $\begin{array}{l}\text { Manchaiah } \\
\text { et } \mathrm{al}^{30}(2015)\end{array}$ & $\begin{array}{l}\text { Examine evidence on positive } \\
\text { experiences associated with } \\
\text { acquired hearing loss, MD and } \\
\text { tinnitus, as reported by those } \\
\text { affected and their significant } \\
\text { others }\end{array}$ & $\begin{array}{l}\text { Literature review based on } \\
\text { electronic search of four } \\
\text { databases up to February } \\
2014 \text {, conducted by two of } \\
\text { the authors independently, } \\
\text { then cross-checked. } \\
\text { Studies included if adult } \\
\text { population ( } \geq 18 \text { years), had } \\
\text { acquired hearing loss, and any } \\
\text { stage in rehabilitation. No study } \\
\text { type or language restriction. }\end{array}$ & $\begin{array}{l}\text { Definition of positive } \\
\text { experiences used in the } \\
\text { review was: "any intrinsic } \\
\text { experience, state or belief, } \\
\text { or extrinsic behavior, event, } \\
\text { or physical or social } \\
\text { structure that people } \\
\text { consider to be a source of } \\
\text { mental, physical, spiritual, } \\
\text { social, or emotional benefit } \\
\text { in their life" (Kentala et al } \\
2008 \text { ). }{ }^{57} \\
\text { Focus on patients within any } \\
\text { stage of rehabilitation } \\
\text { (assessment hearing } \\
\text { rehabilitation, or review). }\end{array}$ & $\begin{array}{l}\text { Varied by study. For MD, as } \\
\text { most studies drew on Ménière } \\
\text { Association members, MD } \\
\text { diagnosis was self-diagnosed }\end{array}$ \\
\hline
\end{tabular}

\begin{tabular}{|c|c|c|c|c|}
\hline $\begin{array}{l}\text { Pyykkö et al }{ }^{35} \\
(20 \mid 4)\end{array}$ & $\begin{array}{l}\text { Report on positive } \\
\text { experiences of significant } \\
\text { others of patients with hearing } \\
\text { and balance disorders }\end{array}$ & $\begin{array}{l}\text { Findings reported in a "Letter } \\
\text { to the Editor" on three } \\
\text { cross-sectional studies, two } \\
\text { conducted in Wales and one } \\
\text { in Finland (MD participants } \\
\text { only) on significant others } \\
\text { of persons with hearing loss, } \\
\text { including MD }\end{array}$ & $\begin{array}{l}\text { Use of open-ended } \\
\text { questionnaire, asking about } \\
\text { the positive experiences of } \\
\text { the significant other }\end{array}$ & $\begin{array}{l}\text { For MD, drawn from } \\
\text { Ménière's Association, thus } \\
\text { not necessarily medically } \\
\text { confirmed MD }\end{array}$ \\
\hline
\end{tabular}

Notes: *Graded according to either the Quality of Study Rating Form (\%) or according to the NICE 2012 quality assessment criteria (+, good quality; ++, highest quality). ${ }^{26,28}$ Abbreviations: MD, Ménière's disease; WLC, wait list control; CBT, cognitive behavioral therapy; FMF, Finnish Ménière's Federation; SD, standard deviation; VR, vestibular rehabilitation; SC, symptom control; CAM, complementary and alternative medicine; SOC, sense of coherence; QoL, quality of life; EQ-5D,s EuroQol 5D (dimensional) quality of life measure.

practitioners (including the fact of diagnosis, advice, or treatment).

\section{CBT health practitioner-designed approaches}

One study in this area, a randomized controlled trial ${ }^{39}$ for those with MD, presented strong evidence on the efficacy of a practitioner-designed self-help education and supported CBT intervention and/or a symptom-control approach using applied relaxation. ${ }^{44}$ Similar levels of symptom improvement were identified for those receiving the CBT self-help intervention and those receiving a symptom-control set of strategies. Both involved persons with MD to use the self-help manual on their own, without practitioner support. Further supportive evidence of the efficacy of such a self-help CBT approach is provided by a recent high quality systematic review $^{21}$ in the allied area of tinnitus, itself a common and disabling feature of MD.

\section{Self-identification: "finding your own way"}

The narrative paper ${ }^{29}$ explored the search for and valued CAM-based supportive approaches reported by persons with MD and had used any CAM therapy. Their accounts demonstrated a diversity of participants' journeys in locating better, and non-biomedical, ways to cope with the illness. Participants pointed to the influence of significant events (eg, increased attack frequency or severity of the condition) and "significant others" (in particular, a family member or friend) in influencing or helping them in their search. A critical theme emerging from the accounts was the personal nature of their search and journey, that is, evidence of self/health-agency approach. ${ }^{12}$ 
Key findings
Summary evaluation comments
Overall
evidence
quality*

This is a well designed literature review, providing an appropriate narrative overview of the evidence, given the thematic nature of the positive experiences reported. The review is conducted in a systematic manner, used appropriate search terms with two authors independently doing the searches in order to reduce chance of missing studies. No studies conducted up to February 2014 appear to have been omitted. However, it is unclear how, or if, each of the included studies was critically appraised. At the same time, useful and appropriate overview comments were providing (eg, sample sources from Ménière's Associations members likely to be more troubled by MD or have more severe symptoms; diagnosis based on case history, not medical diagnosis; convenience samples).

Inclusion criterion was that the person with MD was within the rehabilitation phase. Thus, the study would exclude any studies (if there were any) of persons who were no longer in that phase (eg, seeking alternative treatments on own volition) or their significant others.

The authors' conclusions fit the evidence (there is good evidence on positive experiences for those with acquired hearing loss, MD, and tinnitus). Useful suggestions on rehabilitation implications are drawn, including involvement of significant others and the potential on promoting positive thinking. However, one must caution against whether such an approach is appropriate for all and at any stage in the illness trajectory.

Only limited detail is thus provided on the individual studies (all referenced). The aim is rather to draw readers' attention to evidence on positive experiences of significant others in contrast to commonly exploring the effects, and thus, more likely, negative effects and experiences. Draws out interesting implications for rehabilitation (in particular, involvement of significant others in rehabilitation), drawing on the approach of positive psychology.

quality*

All participants were able to identify one or more positive experiences. For example, participants in the 2013 Finnish study pointed to: improved relationships, acceptance of positive attitude, perspective of MD, treatmentrelated benefits, and information and support provided.
15 studies included of which six, mostly conducted in Finland, related to persons and 2010b;60 Kentala et al 2008.57 Dibb 200961) and two significant others of a person et al $2013^{63}$ ). Average number of positive experience per person across the three positive experiences (26\%-84\%). Positive experiences for significant others positive attitude, and receipt of information on MD.
The second study in this area ${ }^{33}$ drawing on participants' drawn randomly by list sampling found that $87 \%$ of the participants listed one or more self-help techniques (median of 3 ) with most directed at symptom control and improving well-being. The most identified area (59\% of the total number of techniques) was changing/improving their lifestyle, through getting regular sleep, taking more exercise, and dietary modifications. Avoidance of precipitation factors was also noted by $14 \%$ (for example, stress at work or rapid head movements). In addition, "developing a positive approach" was pointed to by $8 \%$, characterized in the phrase "(learning to) get along with it (my disease)".

\section{Sense of coherence}

The two studies in this area ${ }^{31,34}$ demonstrated strong correlations of a higher SOC (that is, the ability to cope in stressful situations) with a higher general and symptomspecific QoL. The latter study, seemingly drawing on the same set of participants as those in Kentala et al, ${ }^{33}$ also reported that those with a low SOC were more likely to be anxious, depressed, and feel less energetic. Those with a higher SOC were more likely to report having a positive attitude to their MD and have a stronger sense of control and self-efficacy.

\section{(Building on) positive experiences}

In a high quality systematic review of positive experiences reported by persons with MD or their significant others, ${ }^{30}$ a wide range of positive experiences were listed by the study participants. The most common were responses related to personal development, appreciation of life, learning how 
Table 2 Underlying theoretical perspectives

\begin{tabular}{|c|c|c|}
\hline Self-help approach & Studies & Theoretical perspective \\
\hline \multirow[t]{2}{*}{$\begin{array}{l}\text { Stress-related } \\
\text { coping strategies }\end{array}$} & Hägnebo et $\mathrm{al}^{31}$ (1999) & $\begin{array}{l}\text { Social-psychological, coping theoretical perspective. Draws on the theories of Folkman and } \\
\text { Lazarus }^{7} \text { and Lazarus }(1993)^{40} \text { on stress, personality and cognitive factors, and coping strategies. }\end{array}$ \\
\hline & $\begin{array}{l}\text { Yardley and Beech }{ }^{20} \\
\text { (1998) }\end{array}$ & $\begin{array}{l}\text { Socio-cultural perspective of coping. This explores the socio-cultural meaning and } \\
\text { intelligibility on ill-health, distress ascribed by the person, with coping behavior interpreted } \\
\text { as a mode of individual-society interaction. Also adopts a post-structuralist, deconstruction } \\
\text { approach with emphasis on "current" representation within the person's (personal and } \\
\text { socio-culturally) embodied life. }\end{array}$ \\
\hline \multirow[t]{2}{*}{$\begin{array}{l}\text { Cognitive } \\
\text { behavioral therapy }\end{array}$} & $\begin{array}{l}\text { Yardley and Kirby }{ }^{38} \\
(2006)\end{array}$ & Cognitive behavioral therapy and behavioral change, with an orientation toward "goal change". \\
\hline & Nyenhuis et $\mathrm{al}^{21}(20 \mid 3)$ & Cognitive behavioral therapy, psychological perspective. \\
\hline \multirow[t]{2}{*}{$\begin{array}{l}\text { Self-identification: } \\
\text { "finding your own } \\
\text { way" }\end{array}$} & $\begin{array}{l}\text { Long and Bennett }{ }^{29} \\
(2009)\end{array}$ & $\begin{array}{l}\text { Illness disruption and coping for persons experiencing chronic illness (Bury,' Williams }{ }^{3} \text { ); } \\
\text { whole person, mind-body perspective, drawn from complementary and alternative } \\
\text { medicine; }{ }^{42} \text { and narratives based on Frank's }{ }^{36,37} \text { interpretation of a narrative as an individual's } \\
\text { "interpretation of their situation" at the time of its construction/writing. }\end{array}$ \\
\hline & Kentala et $\mathrm{al}^{33}(2013)$ & $\begin{array}{l}\text { Unclear. Empirically focused to uncover individuals' self-help techniques. At least implicitly } \\
\text { drawing on the notion of self/health agency. }\end{array}$ \\
\hline \multirow[t]{2}{*}{$\begin{array}{l}\text { Sense of coherence } \\
\text { (SOC) }\end{array}$} & Söderman et al ${ }^{32}(200 \mathrm{I})$ & $\begin{array}{l}\text { Drawing on Antonovsky's concepts of salutogenesis (the origin of health and associated } \\
\text { concept of the SOC). Moving beyond a perception of coping as mechanism as buffers or } \\
\text { moderators as stressors are ubiquitous in society. A focus on the means of helping oneself } \\
\text { through the difficulties of life. Recognition of importance of societal, thus structural, factors } \\
\text { as potentially enabling and constraining factors. Antonovsky:19l defines SOC as "a global } \\
\text { orientation that expresses the extent to which one has a pervasive, enduring though } \\
\text { dynamic feeling of confidence that: I) the stimuli deriving from one's internal and external } \\
\text { environments in the course of living are structured, predictable, and explicable; } 2 \text { ) the } \\
\text { resources are available to one to meet the demands posed by these stimuli; and } \\
\text { 3) these demands are challenges, worthy of investment and engagement". }\end{array}$ \\
\hline & Ketola et $\mathrm{al}^{34}(2014)$ & $\begin{array}{l}\text { The SOC thus has three main components: i) the ability to understand what is happening } \\
\text { (cognitive component); ii) the manageability of life situations in social networks (manageability } \\
\text { component); and iii) the ability to find a meaning in life (meaningfulness component). }\end{array}$ \\
\hline Positive experiences & $\begin{array}{l}\text { Manchaiah et } \mathrm{al}^{30}(2015) \\
\text { Pyykkö et al }{ }^{35}(2014)\end{array}$ & $\begin{array}{l}\text { Positive psychology: }{ }^{41} \text { A branch of psychology which aims to understand and enhance human } \\
\text { strengths (eg, personal traits, creativity, joy, flow, responsibility, optimal performance, and } \\
\text { achievement). It is the scientific study of what makes life worth living and "happiness". In a } \\
\text { health/illness context, focus lies on exploring how people in general and persons with chronic } \\
\text { or mental health illness can become happier, more resilient, and more fulfilled. Identifying } \\
\text { perceived positive experiences provides an important empirical starting point. }\end{array}$ \\
\hline
\end{tabular}

to manage and live with their MD (for example, by accepting their limitations), and more general personal changes. Positive experiences were also reported by the significant others of persons with MD. These included: benefit due to the person with MD being able to cope better or having more positive thoughts about the condition and information that they as significant others as potential informal carers received from health care practitioners. At the same time, many also reported substantial impact of the person with MD on themselves. Effects (thus, negative experiences) ranged from limitations of their own activities, dietary changes, and more general uncertainty of their and the other person's life. The other paper in this area ${ }^{35}$ reported on findings from two survey studies conducted in Finland and Wales on positive experiences listed by significant others. Their findings echoed those reported in the systematic review.

\section{Discussion}

The evidence presented in this systematic review of self-care/ self-help strategies, summarized in Table 3, demonstrates a multiplicity of approaches tried, and in many cases found useful, in helping persons with MD enhance their coping with the condition and its QoL impacts on their life. The range of theoretical perspectives underlying the eight studies is noteworthy suggesting the potential of application of a multi-disciplinary perspective to guide research and inform practice interventions. Across all the studies, irrespective of the underlying theoretical perspective, the findings pointed toward pursuit of self-health agency and the need to search for oneself, with support from significant others and supportive health care practitioners, for ways to regain control over their ill-health (empowerment) and life in general, within the individual's own socio-cultural lifeworld and informed by their own self-resiliency and/or psychological cognitive and 


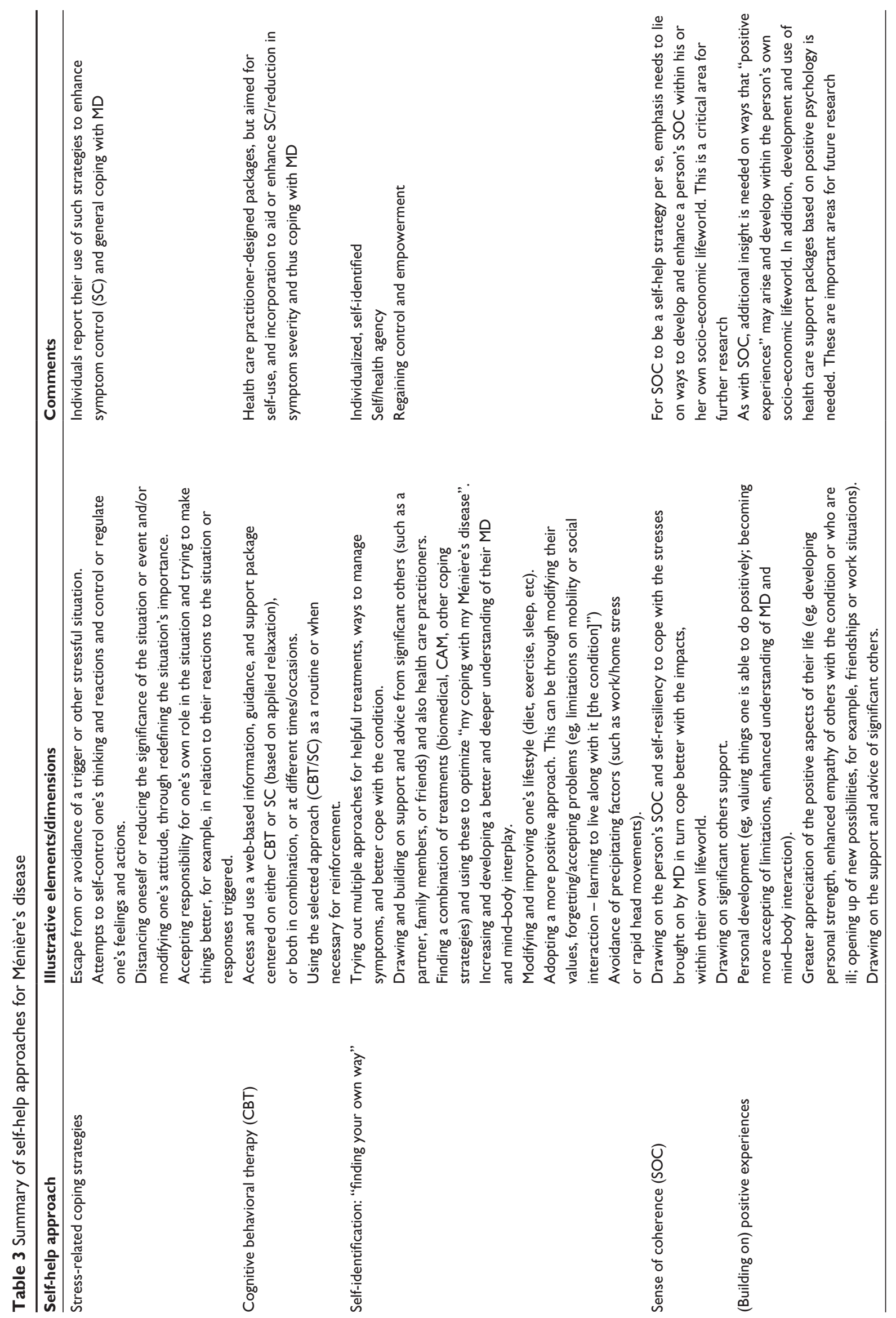


emotional resources. No single self-care/self-help strategy or coping mechanism was evident.

It is however valuable to reflect on the ways in which two of the above strategies might become self-help strategies that others can utilize. Firstly, in relation to findings of "positive experiences" by those with MD (or living with another chronic illness), their statements are suggestive of evidence of successful, either fully or partially, of the development of coping strategies and mechanisms that enables a more positive outlook. The examples noted in the studies, and in literature more generally, point to areas such as "greater understanding of my body", "learning how to live my life", or "learning about the illness". In this sense, "developing a positive attitude" is not in itself a self-help strategy; it may rather be understood as one end of a journey, representing "now that I feel more able to cope, these elements that were found helpful". These are now and appropriately perceived as positive.

Secondly, in relation to SOC, from its origin within Antonovsky's salutogenesis approach, ${ }^{5}$ a higher SOC is both something one may possess (for example, from upbringing, social status, and socio-economic circumstances) and something that in principle one can develop, given appropriate resources (social, personal, and societal). As such, neither study included in this systematic review addresses or provides insight into how SOC can be enhanced, and thus become a possible "self-help" strategy for others. It is also important to remember that SOC, and the search for why some remain healthy and others not, is interlinked with structural (wider societal, economic, and cultural) factors over which the particular person may have little or no control or influence. ${ }^{45}$

A major area for future research is the development of greater insight into how the particular self-help strategy is both identified by the person and ways in which that strategy can be developed for others with MD. As noted above, this is particularly the case for the two areas of the SOC and perceptions of positive experiences. This could valuably identify factors that enable the development of the coping strategy (for example, with the support of family or friends) and factors that may inhibit or constrain its development. An inhibiting factor might be centered within the persons with MD (their openness and readiness to change). ${ }^{46,47} \mathrm{~A}$ constraining factor could be social-economic, for example, an unsupportive social benefits system (eg, reassessment of eligibility for a disability living allowance or non-recognition of MD as an illness that meets the criteria for social security support).

Of equal importance is the development and evaluation of the effectiveness of treatments or packages, designed and/or delivered by health care and/or CAM practitioners, which are directed toward the development of the coping strategy (eg, "developing a more positive attitude") and their incorporation into the self-help strategies used by the person with MD. As Manchaiah et $\mathrm{al}^{30}$ comment, development of a positive approach could be followed through and become an important part of any rehabilitation and support program directed at promoting positive thinking, involving their significant others as appropriate. Again, however, patients participating in such a program need to be open and ready to change, that is, open to notions about thinking more positively about their MD and thus able to reflect and identify positives in the future. In addition, there are a number of other evidence-based approaches, for example, development of mindfulness ${ }^{48}$ or the incorporation of other CAM treatments (for example, yoga and meditation) that can be used.

Two related concepts are helpful here in reflecting on these findings. Firstly, as depicted by Quah, ${ }^{49}$ features of "pragmatic acculturation" are evident. Pragmatic acculturation involves the borrowing of ideas, and ways of thinking and acting from multiple cultures in order to help solve a problem. Both bio-medicine and CAM are in essence different health care cultures ${ }^{35,51}$ and the different theoretical perspectives are different ways of thinking about the world. In this sense, as demonstrated in the reviewed studies, persons with MD are pragmatic in their approaches in seeking self-care strategies and approaches, drawing out, potentially through the heuristic process of trial-and-error, ${ }^{29}$ what "works" for them. A second useful concept is the notion of health literacy ${ }^{52}$ and the health capability model, which is based on the notion that people seek good health and the ability to be healthy. ${ }^{53}$ Health literacy can be defined as "a range of skills and competencies that people develop over time to seek out, comprehend, evaluate and use health information ... to make informed choices". ${ }^{54}$ It becomes a key priority with the added aim of enhancing the sense of control of the persons over their own health and their health decision-making.

Drawing definitive guidance to assist both persons with MD and/or health care or CAM practitioners about options to focus on is thus difficult. A range of valued approaches are evident in this review of the literature (Table 3). On the one hand, there is strong evidence, though as yet only one study within MD, on CBT-health care practitioner-designed self-help approaches. ${ }^{38}$ On the other hand, studies depict a multiplicity of potential coping strategies that might help one or another person varying by inter alia a person's social psychological and/or broader socio-cultural resources and support networks. ${ }^{29-35}$ All demonstrate pursuit of a self- 
health agency approach and search to gain greater control over one's life, that is, "finding one's own way". Moreover, there is considerable potential and value in adoption of a "whole-person" conception and model of (ill-) health, healing and well-being, centered on enhancing people's self- and guided awareness of their own body, life-style (including diet and exercise) and self-resiliency within the context of the individual's socio-economic-political and cultural lifeworld. ${ }^{55}$

This review has both strengths and weaknesses. Key strengths include the systematic search for evidence, conducted in a rigorous and transparent manner, and rigorous critical appraisal and quality assessment of the included studies. A potential weakness lies in the limited number of electronic data bases searched and limited handsearching of key journals. At the same time, the strict focus of the review on self-care/self-help approaches for MD per se narrows the potential evidence base.

\section{Conclusion}

In summary, the key message for persons with MD and health and other care practitioners in discussing treatment options with patients is the multiplicity of potential strategies and, albeit problematically, to try with support from others to "find what works, why and how" for that person in their own psychological-socio-cultural lifeworld. Due to the small number of studies eligible for inclusion in the systematic review and their heterogeneity, further research is warranted in this area. It would be valuable to explore the journey of persons with MD in their search for self-care/ self-help strategies and coping mechanisms and, in particular, gain greater insight into how the self-help strategy is developed, and why they find the set of strategies and mechanisms helpful and for which of their multiple symptoms. A multi-disciplinary research approach is needed. This could valuably draw on the notions of pragmatic acculturation, health literacy, and self/health agency. In addition, there is a need for further research on the potential of, and who might benefit the most from, practitioner-designed (and/or with patient guidance) CBT-self-help and other (for example, promotion of "positive thinking" or "thinking in the moment") interventions.

\section{Disclosure}

The authors report no conflicts of interest in this work.

\section{References}

1. Bury M. Chronic illness as biographical disruption. Sociol Health Illn. 1982;4:165-182.
2. Bury M. Meanings at risk: the experience of arthritis. In: Anderson R, Bury M, editors. Living With Chronic Illness: The Experience of Patients and Their Families. London: Unwin Hyman; 1988:89-116.

3. Williams SJ. Chronic illness as biographical disruption or biographical disruption as chronic illness? Reflections on a core concept. Sociol Health Illn. 2000;22(1):40-67.

4. Saunders C, Donovan J and Dieppe P. The significance and consequences of having painful and disabled joints in older age: co-existing accounts of normal and disrupted biographies. Sociol Health Illn. 2002;24(2):227-253.

5. Antonovsky A. Unravelling the Mystery of Health: How People Manage Stress and Stay Well. San Francisco: Jossey-Bass; 1987.

6. Evans RG, Barer ML, Marmor TR, editors. Why are Some People Healthy and Others Not? The Determinants of Health of Populations. New York: Aldine de Gruyter; 1996.

7. Folkman $\mathrm{S}$ and Lazarus RS. The relationship between coping and emotion: Implications for theory and research. Social Science and Medicine. 1988;26(1):309-317.

8. Weiten W, Lloyd MA. Psychology Applied to Modern Life. Stanford, CA: Wadsworth, Cengage Learning; 2008.

9. Schreurs K, de Ridder D. Integration of coping and social support perspectives: implications for the study of adaptation to chronic diseases. Clin Psychol Rev. 1997;17(1):89-112.

10. Bandura A. Self-efficacy mechanism in human agency. Am Psychol. 1982;37(2):122-147.

11. Sen A. Human rights and capabilities. J Hum Develop. 2005;6(2): 151-166.

12. Narayan D, editor. Measuring Empowerment: Cross-Disciplinary Perspectives. Washington, DC: Open University Press; 2005.

13. Rijken M, Jones M, Heumans M, Dixon A. Supporting self-management. In: Nolte E, McKee M, editors. Caring for People with Chronic Conditions: A Health System Perspective. Maidenhead: Open University Press McGraw Hill; 2008.

14. Lorig KR, Holman HR. Self-management education: history, definition, outcomes, and mechanisms. 2003; Ann Behav Med. 2003;26(1):1-7.

15. Godfrey CM, Harrison MB, Lysaght R, Lamb M, Graham ID, Oakley P. Care of self - care by other - care of other: the meaning of self-care from research, practice, policy and industry perspectives. Int $J$ Evid Based Healthc. 2011;9(1):3-24.

16. Hain TC. Epidemiology of Ménière's disease (updated June 19, 2015). Available from: http://www.dizziness-and-balance.com/disorders/ menieres/men_epi.html. Accessed July 30, 2015.

17. Saeed SR. Diagnosis and treatment of Ménière's disease. $\mathrm{Br}$ Med J. 1998;316(7128):368-372.

18. PDxMD. Ear, Nose and Throat Disorders. Philadelphia: Elsevier Science; 2003.

19. Hain TC. Ménière's disease (updated June 7, 2015). Available from: http://www.dizziness-and-balance.com/disorders/menieres/menieres html\#common. Accessed July 30, 2015.

20. Yardley L, Beech S. I'm not a doctor': deconstructing accounts of coping, causes and control of dizziness. J Health Psychol. 1998;3(3): 313-327.

21. Nyenhuis N, Golm D, Kröner-Herwig B. A systematic review and meta-analysis on the efficacy of self-help interventions in tinnitus. Cogn Behav Ther. 2013;42(2):159-169.

22. Centre for Reviews and Dissemination (CRD). Systematic Reviews: CRD's Guidance for Undertaking Reviews in Health Care. York: University of York; 2009.

23. Boonstra A, Versluis A and Vos JFJ. Implementing electronic health records in hospitals: a systematic literature review. BMC Health Serv Res. 2014;14:370.

24. Long AF. Critically appraising research studies. In: McSherry APR, Simmons M, editors. Evidence-Informed Nursing. A Guide for Clinical Nurses. London: Routledge; 2002:41-64.

25. Long AF, Godfrey M. An evaluation tool to assess the quality of qualitative research studies. Int J Soc Res Methodol. 2004;7(2):181-196.

26. Gibbs LE. Quality of study rating form: an instrument for synthesizing evaluation studies. $J$ Soc Work Educ. 1989;25(1):55-67. 
27. Gibbs LE. Evidence-Based Practice for the Helping Professions: a Practical Guide with Integrated Multi-Media. Pacific Grove, CA: Brooks/Cole-Thomson Learning; 2003.

28. National Institute of Health and Clinical Excellence. Public Health Guidance: Development Process and Methods. 3rd ed. London: NICE; 2012.

29. Long AF and Bennett T. Coping with Ménière's disease: experience and benefits from the use of complementary and alternative medicine. Chronic Illness. 2009;5(3):219-232.

30. Manchaiah VKC, Bagulaey DM, Pyykkö I, Kentola E, Levo H. Positive experiences associated with acquired hearing loss, Ménière's disease, and tinnitus: a review. Int J Audiol. 2015;54:1-10.

31. Hägnebo C, Melin L, Andersson G. Coping strategies and anxiety sensitivity in Ménière's disease. Psychol Health Med. 1999;4(1):17-26.

32. Soderman AC, Bergenius J, Bagger-Sjoback D, Tjell C, Langius A. Patients' subjective evaluations of quality of life related to diseasespecific symptoms, sense of coherence, and treatment in Ménière's disease. Otol Neurotol. 2001;22:526-533.

33. Kentala E, Levo H, Pyykkö I. How one hundred and eighty three people with Ménière's disorder relieve their symptoms: a random cohort questionnaire study. Clin Otolaryngol. 2013;38(2):170-174.

34. Ketola S, Levo H, Rasku J, Pyykkö I. The sense of coherence in patients with Ménière's disease. Auris Nasus Larynx. 2014;41(3):244-248.

35. Pyykkö I, Manchaiah VKC, Kentala E, Levo H. Significant others of patients with hearing and balance disorder report positive experiences. Int $J$ Audiol. 2014;53:285-286.

36. Frank AW. The Wounded Storyteller: Body, Illness and Ethics. Chicago: University of Chicago Press; 1995.

37. Frank AW. Just listening: narratives and deep illness. Fam Syst Health. 1998;16:197-212.

38. Yardley L, Kirby S. Evaluation of booklet-based self-management of symptoms in Ménière's disease: a randomized controlled trial. Psychosom Med. 2006;68:762-769.*

39. Dibb B, Yardley L. Factors important for the measurement of social comparison in chronic illness: a mixed-methods study. Chronic Illn. 2006;2(3):219-230.

40. Lazarus RS. (1993). Coping theory and research: past, present, and the future. Psychosom Med. 1993;55(3):234-247.

41. Snyder CR, Lopez SJ, editors Handbook of Positive Psychology. New York: Oxford University Press; 2002.

42. Verhoef MF, Lewith G, Ritenbaugh C, Boon H, Fleishman S, Leis A. Complementary and alternative medicine whole systems research: beyond identification of inadequacies of the RCT. Complement Ther Med. 2005;3:206-212.

43. Long AF. Complementary and alternative medicine (CAM) and the public health: an innovative healthcare practice in supporting and sustaining health and well-being. Epidemiol. 2013;4:141.

44. Öst LG. Applied relaxation: description of a coping technique and review of controlled studies. Behav Res Ther. 1987;25(5):397-409.

45. Erikson M, Lindström. Antonovsky's sense of coherence scale and its relation with quality of life: a systematic review. J Epidemiol Community Health. 2007;61:938-944.
46. Dalton C, Gottlieb LN. The concept of readiness to change. JAdv Nurs. 2003;42:108-117.

47. Honda K, Jacobson JS. Use of complementary and alternative medicine among United States adults: the influences of personality, coping strategies, and social support. Prev Med. 2005;40:46-53.

48. Philippot P, Nef F, Clauw L, de Romrée M, Segal Z. A randomized controlled trial of mindfulness-based cognitive therapy for treating tinnitus. Clin Psychol Psychother. 2012;19(5):411-419.

49. Quah SR. In pursuit of health: pragmatic acculturation in everyday life. Health Sociol Rev. 2008;17(4):419-422.

50. Helman CG. Culture, Health and Illness. 5th ed. London: Hodder Headline Group; 2007.

51. Kleinman A. The Illness Narratives. Suffering, Healing and the Human Condition. USA: Basic Books; 1988.

52. Nutbeam D. Health literacy as a public health goal: a challenge for contemporary health education and communication strategies into the 21st century. Health Promot Int. 2000;15:259-267.

53. Ruger JP. Health capability: conceptualization and operationalization. Am J Public Health. 2010;100(1):41-49.

54. Zarcadoolas C, Pleasant A, Greer DS. Understanding health literacy: an expanded model. Health Promot Int. 2005;20:195-203.

55. Rubinelli S, Schulz PJ, Nakamoto K. Health literacy beyond knowledge and behaviour: letting the patient be a patient. Intl J Health. 2009;54:(5)307-311.

56. Stephens D, Kentala E, Varpa K, Pyykkö I. Positive experiences associated with Ménière's disorder. Otology and Neurotolology 2007;28:982-987.

57. Kentala E, Wilson C, Pyykkö I, Varpa K, Stephens D. Positive experiences associated with tinnitus and balance problems. Audiological Medicine 2008;6:55-61.

58. Stephens D, Pyykkö I, Varpa K, Kentala E. The relationship between positive experiences in people with Ménière's disorder and the impact of the condition. Audiological Medicine 2009; 7:233-240.

59. Stephens D, Pyykkö I, Kentala E, Levo H. Positive experiences reported by people with Ménière's disorder: A quantitative study. Acta OtoLaryngologica 2010a;130:1013-1018.

60. Stephens D, Pyykkö I, Poe D, Kentala E, Auramo Y. 2010b . Positive experiences and quality of life in Ménière's disorder. International Journal of Audiology 2010b;49:839-843.

61. Dibb B. Positive change with Ménière's disease. British Journal of Health Psychology, 2009;14:613-624.

62. Stephens D, Pyykkö I, Kentala E, Levo H, Rasku J. The effect of Ménière's disorder on the patient's significant others. International Journal of Audiology, 2012;51:858-863.

63. Manchaiah VKC, Pyykkö I, Kentala E, Levo H, Stephens D. Positive impact of Ménière's disorder on significant others as well as on patients: experience from eighty-eight respondents. Clinical Otolaryhgology 2013;38:553-556 


\section{Supplementary material}

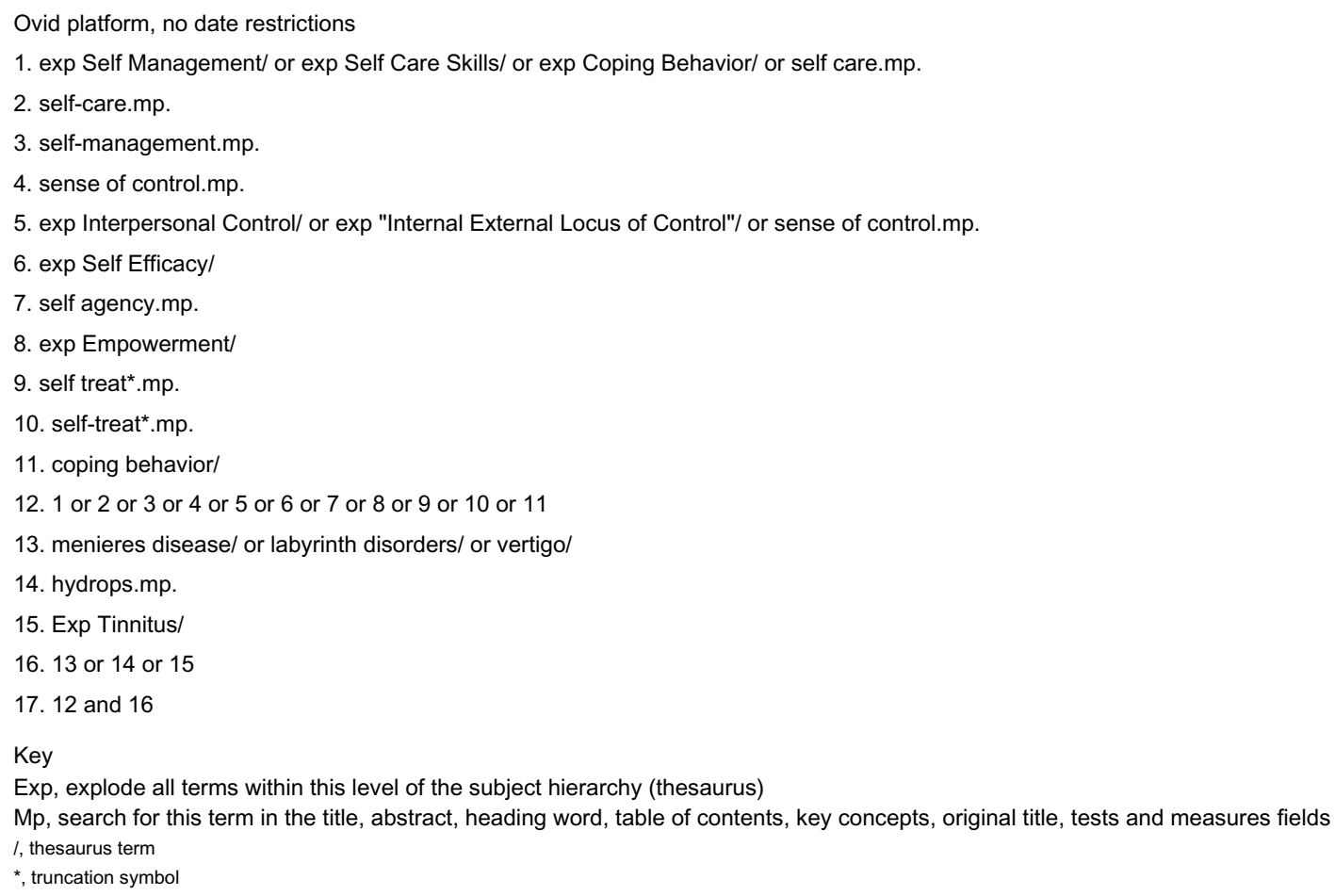

Figure SI Sample search strategy - PsycINFO. 
Table SI Critical appraisal of efficacy of self-help interventions for tinnitus and vertigo

\section{Tinnitus and vertigo: common elements in Ménière's disease}

Nyenhuis Examine the efficacy of cognitive

et al (20I3) behavioral therapy (CBT) self-help

interventions on tinnitus distress

and value of face-to-face vs other

(eg, only information, discussion forums)

Examine the socio-cultural

functions of accounts of coping

and coping-related beliefs offered

by people suffering from vertigo and Beech

(1998)
Systematic review of randomized controlled trials (RCTs)

No country limitation

Four electronic databases (up to February 2012), contacting key authors in field and manual search using search terms of tinnitus and self-help interventions

Qualitative, interview-based study UK (south-east)

Consecutive sample of persons, eligible and referred for a RCT of benefits of exercise therapy for vertigo
CBT self-help intervention (standardized manual explored independently by the individual)

Passive control (face-to-face treatments or online discussion forums)

10 studies included in the meta-analysis. Resulted in I 188 participants, on average 49 years old 
Yes, within each of the included studies in the systematic review. Overall, average of 5.2 years
CBT self-help interventions significantly reduced tinnitus distress and depressiveness in comparison with passive controls at post-treatment assessment. There was no difference between the self-help treatment or face-to-face treatment. But, the overall quality of RCTs was low in general.
Yes

Length of time with dizziness, not stated
Two main coping strategies were mentioned by most participants: those involving the doctor $(n=34$; diagnosis, advice, or treatment) and physical $(n=33$; eg, avoiding or restricting activity, sitting/lying down, holding on to a support). The next three most prevalent accounts related to either seeing $(n=28)$, or coping through ignoring and carrying on or asserting the need to be positive and independent $(n=25)$, or coping by depending on others $(n=24$; eg, family, neighbors). Nine mentioned diet-related changes (salt, pork, and cheese), smoking, and homeopathy. The accounts and discourse used demonstrated participants' perceptions of their having a chronic illness, being physically ill but socially responsible to attempt to find ways to cope.
This is a well designed and soundly conducted systematic and meta-analytical review of RCTs meeting the eligibility criteria and published up by February 2012. Two authors Independently examined paper relevance and the critical appraisal of included studies. High quality and appropriate statistical analysis is conducted, including a sensitivity analysis (which suggests a possible publication bias).

The authors point to some study limitations, including: conceptual heterogeneity on the nature of a self-help interventions and the overall low study quality, suggesting the need for more RCTs of high quality. The authors' conclusions (self-help interventions with little or no therapist contact are as efficacious as face-to-face treatments) fit the evidence.

A well designed and conducted qualitative study, based on a selected sample (all of whom were eligible and future participants in an RCT) and tape-recorded interview (length 20-60 minutes), following a set of pilot interviews. A sound and appropriate theoretical and inferential perspective is followed through and good evidence of the meaning and appropriateness of the content analysis of coping strategies and possible self-perceived causes of discourse.

The authors' discussion and conclusions fit the evidence presented (coping styles having a behavior and sociolinguistic component, strongly influenced by Western ideas about the body, as "misbehaving" while in contrast individuals were facing having to cope with an altered state of being).

Notes: Graded according to relevant items in the Quality of Study Rating Form, summed and presented as \% of maximum possible for set of items; graded on three-point scale, ++ high quality; + good quality; and - low quality, according to NICE quality assessment criteria.'

\section{Reference}

1. National Institute of Health and Clinical Excellence. Public Health Guidance: Development Process and Methods. 3rd ed. London: NICE; 2012 .

\section{Publish your work in this journal}

Patient Intelligence is an international, peer-reviewed, open access journal that characterizes and measures the central role of patient behavior and intention in optimizing healthcare management in all areas of disease and complaint types. An improved understanding of patient intelligence coupled with predictive analysis helps an organization contribute more effectively to achieving better outcomes.

Submit your manuscript here: http://www.dovepress.com/patient-intelligence-journal

\section{Dovepress}

The journal is characterized by the rapid reporting of reviews, original research, methodologies, analytics, modeling, clinical studies and patient surveys across all disease areas. The manuscript management system is completely online and includes a very quick and fair peer-review system. Visit http://www.dovepress.com/ testimonials.php to read real quotes from published authors. 